\title{
Diet of the chaetognaths Sagitta setosa and $S$. elegans in relation to prey abundance and vertical distribution
}

\author{
Kajsa Tönnesson*, Peter Tiselius \\ Department of Marine Ecology, Göteborg University, Kristineberg Marine Research Station, 45034 Fiskebäckskil, Sweden
}

\begin{abstract}
The chaetognaths Sagitta setosa and S. elegans and their potential prey organisms were collected from 6 different depth strata on 6 day and night occasions in the Gullmar fjord, west Sweden. The chaetognaths were analysed for gut contents and predation impact estimated. Number of prey per chaetognath (NPC) ranged from 0.2 to 1.0 for $S$. setosa and 0.4 to 0.9 for $S$. elegans, with significantly higher values at night. For S. setosa, small copepods dominated gut contents, with the addition of the appendicularian Oikopleura dioica and chaetognaths later in the season. For S. elegans, the great majority of prey were Calanus copepodites. Predation impact was strong on single copepod species, increasing from 0.4 to a maximum of $48 \%$ of the individuals removed daily by $S$. setosa at the end of October. S. elegans consumed 5 to $18 \%$ of the deeper dwelling Calanus community daily. Cannibalism was pronounced in S. setosa; in October, 74 to $84 \%$ of the population could potentially be removed each day. Selective feeding was observed in $S$. setosa by estimating clearance rates for different prey. Pseudocalanus sp. was over-represented in the guts (clearance $120 \mathrm{ml} \mathrm{ind.}^{-1}$ $\mathrm{d}^{-1}$ ) as well as $S$. setosa (124 ml ind..$\left.^{-1} \mathrm{~d}^{-1}\right)$ and Paracalanus parvus $\left(40 \mathrm{ml}\right.$ ind..$\left.^{-1} \mathrm{~d}^{-1}\right)$. S. setosa was able to maintain a daily ration of 11 to $17 \%$ of body weight despite a rapid decline in copepod prey abundance, and this was possible through cannibalism and intense predation on $O$. dioica.
\end{abstract}

KEY WORDS: Predator-prey interactions · Predation impact · Cannibalism · Population dynamics

\section{INTRODUCTION}

Chaetognaths are important zooplankton predators in the sea (Reeve 1980, Feigenbaum \& Maris 1984, Baier \& Purcell 1997b). Most are ambush feeders and detect prey by sensing hydrodynamic signals (Feigenbaum \& Reeve 1977). The sensitivity of the mechanoreceptors sets the minimum prey size, while the maximum prey size is set by the mouth opening (Pearre 1980, Sullivan 1980). Small prey such as tintinnids and rotifers may be important in the diet of young chaetognaths (Pearre 1973, 1981), but the main diet consists of copepod nauplii and copepodites (Feigenbaum \& Maris 1984, Feigenbaum 1991, Duró \& Saiz 2000). Barnacle nauplii, appendicularians, chaetognaths, cladocerans and fish larvae all contribute to the diet periodically (Rakusa-Suszczewski 1967, Pearre 1974, Feigenbaum \& Maris 1984, Øresland 1987). Chaeto- gnaths show selectivity in their feeding behaviour and the selection may be based on size, shape, differential movement pattern or escape capability of prey (Pearre 1974, Feigenbaum 1991, Alvarez-Cadena 1993, Saito \& Kiørboe 2001).

Sagitta elegans Verrill and S. setosa J. Müller are the 2 dominant chaetognath species in European shelf waters. In the Gullmar fjord, west Sweden, S. elegans occur throughout the year, while $S$. setosa is only common in late summer and autumn (Øresland 1983, 1985). Feeding of Sagitta spp. has been studied in the fjord previously (Øresland 1987), but the question of selectivity remains unanswered. This is due to a lack of simultaneous data on vertical distribution and cooccurrence of prey and predators, which is necessary information to show selectivity. The vertical distribution and co-occurrence are also key factors in the estimation of the predation impact. Coincident with peak 
chaetognath abundance in the autumn, copepod populations decline rapidly and chaetognath predation impact might be high. Finally, the strong cannibalism displayed in several chaetognaths has been suggested to be an important factor for the rapid population decline of $S$. setosa in late autumn (Øresland 1987), but this effect has not been quantified.

In the present study, the diets of the 2 chaetognaths were determined on 6 day/night sampling occasions during the autumn. Simultaneously, prey composition and vertical distribution were determined and used to estimate predation pressure and selective feeding.

\section{MATERIALS AND METHODS}

Study area. The study was conducted in the Gullmar fjord, a relatively shallow fjord $(120 \mathrm{~m}$, entrance sill = $45 \mathrm{~m}$ ) on the west coast of Sweden. The water column is permanently stratified with a surface layer (0 to $20 \mathrm{~m}$ ) of variable salinity (15 to $27 \%$ ), an intermediate layer ( 20 to $50 \mathrm{~m} ; 27$ to $32 \%$ ) and a stagnant deep layer (50 to $120 \mathrm{~m} ; 32$ to $34 \%$ ). The conditions in the upper $50 \mathrm{~m}$ of the fjord resemble the surrounding coastal waters. For a more detailed description of the fjord, see Øresland (1985). Sampling was conducted in the central and deepest part of the fjord $\left(58^{\circ} 19.2^{\prime} \mathrm{N}\right.$, $11^{\circ} 32.8^{\prime} \mathrm{E}$ ) on 6 occasions from 6 August to 15 December 1998.

Sampling scheme. Temperature and salinity were measured on each sampling occasion by CTD casts (Type ME OTS 1500). Zooplankton were sampled by sequential duplicate vertical hauls with $90 \mu \mathrm{m}$ WP-2 closing net during the day and night (Table 1). Volume of filtered water was monitored by a calibrated GO flow meter mounted in the net opening. The net was towed in 6 depth strata, 0-10, 10-20, 20-30, 30-40, $40-50$ and $50-110 \mathrm{~m}$ with a towing speed of 0.5 to $1 \mathrm{~m} \mathrm{~s}^{-1}$. All samples were immediately preserved in $4 \%$ formaldehyde in seawater buffered with borax. To minimize cod-end feeding or regurgitation of prey, the tows were kept short (towing time ca. $20 \mathrm{~s}$ ), and the handling time for emptying and fixation kept to a minimum (Baier \& Purcell 1997a).

Zooplankton analysis. Samples for ambient prey concentration were sub-sampled (1/10 to $1 / 100$, Kott 1953) and zooplankton were identified to species level and development stages. At least 10 to 20 individuals of each species at each depth interval were measured. Nauplii were enumerated but not identified to species level.

Chaetognaths were identified according to Jakobsen (1971) and Øresland (1987). The number of investigated chaetognaths ranged from 224 to 2518 on each date. Due to high abundances in September and October, chaetognaths were sub-sampled in the 0-10 m samples (5/10 of the sample on 23 September and 3/10 on 1 and 21 October). All other samples were analysed entirely. Body length was measured from the tip of the head to the end of the tail, excluding the tail fin. Length measurements were not corrected for shrinkage.

For mandible analyses, each chaetognath was dissected in a few drops of polyvinyl-lactophenol. The position of all prey in the gut was noted according to Øresland (1987, his Fig. 1) and the number of prey per chaetognath (NPC) was determined. Individuals containing prey only in the forward $1 / 3$ of the gut (Position 1) were considered empty, and were not included in further analyses, because of the possibility of cod-end feeding (Øresland 1987, Baier \& Purcell 1997a). Prey organisms were identified to species level and stage,

Table 1. Sagitta setosa. Sampling times, day length, number of prey per chaetognath (NPC \pm SD), digestion time (DT, 0-10 m/10-20 m, h) and integrated abundance (ind. $\mathrm{m}^{-2}, 0$ to $20 \mathrm{~m}$ ) of $S$. setosa and important prey. NPC is averaged over the 2 depth intervals $0-10$ and $10-20 \mathrm{~m}$

\begin{tabular}{|c|c|c|c|c|c|c|c|c|c|c|c|c|}
\hline \multirow{3}{*}{$\begin{array}{r}\text { Date: } \\
\text { Sampling time: }\end{array}$} & \multicolumn{2}{|c|}{6 Aug } & \multicolumn{2}{|c|}{$14 \mathrm{Sep}$} & \multicolumn{2}{|c|}{$23 \mathrm{Sep}$} & \multicolumn{2}{|c|}{01 Oct } & \multicolumn{2}{|c|}{21 Oct } & \multicolumn{2}{|c|}{$15 \mathrm{Dec}$} \\
\hline & $10: 45$ to & $22: 00$ to & $10: 15$ to & 22:00 to & $14: 15$ to & 21:00 to & $10: 15$ to & 21:00 to & $10: 15$ to & $20: 15$ to & $09: 30$ to & 20:00 to \\
\hline & $12: 00 \mathrm{~h}$ & $23: 20 \mathrm{~h}$ & $11: 40 \mathrm{~h}$ & $23: 40 \mathrm{~h}$ & $15: 15 \mathrm{~h}$ & $22: 35 \mathrm{~h}$ & $11: 30 \mathrm{~h}$ & $22: 15 \mathrm{~h}$ & $11: 40 \mathrm{~h}$ & $21: 55 \mathrm{~h}$ & $11: 00 \mathrm{~h}$ & $21: 30 \mathrm{~h}$ \\
\hline Sunrise, sunset & $04: 17 \mathrm{~h}$ & $20: 18 \mathrm{~h}$ & 05:39 h & $18: 35 \mathrm{~h}$ & $05: 58 \mathrm{~h}$ & $18: 10 \mathrm{~h}$ & $06: 15 \mathrm{~h}$ & $17: 47 \mathrm{~h}$ & $06.59 \mathrm{~h}$ & $16: 53 \mathrm{~h}$ & $08: 49 \mathrm{~h}$ & $15: 25 \mathrm{~h}$ \\
\hline NPC & $0.56 \pm 0.24$ & $0.76 \pm 0.24$ & $0.38 \pm 0.20$ & $0.68 \pm 0.25$ & $0.34 \pm 0.14$ & $0.91 \pm 0.18$ & $0.48 \pm 0.06$ & $0.64 \pm 0.17$ & $0.51 \pm 0.17$ & $0.88 \pm 0.20$ & $0.28 \pm 0.05$ & $0.51 \pm 0.10$ \\
\hline DT & $2.7 / 3.6$ & $2.7 / 3.6$ & $3.3 / 3.2$ & $3.3 / 3.2$ & 3.3 & 3.3 & 3.4 & 3.4 & 3.4 & 3.4 & 4.8 & 4.8 \\
\hline \multicolumn{13}{|c|}{ Abundance (ind. $\mathrm{m}^{-2}, 0$ to $20 \mathrm{~m}$ ) } \\
\hline Sagitta setosa & 200 & 250 & 1920 & 2890 & 3010 & 3360 & 4810 & 4230 & 4090 & 3550 & 510 & 300 \\
\hline Paracalanus parvus & 62480 & 68070 & 42010 & 42980 & 32770 & 37170 & 12110 & 10060 & 4400 & 2220 & 2320 & 2520 \\
\hline Pseudocalanus sp. & 41930 & 32860 & 21460 & 16790 & 10580 & 10880 & 3420 & 4580 & 4190 & 2890 & 2500 & 3420 \\
\hline Acartia clausi & 14220 & 13490 & 10880 & 13900 & 7260 & 6780 & 3810 & 3670 & 3170 & 2830 & 230 & 260 \\
\hline Oithona & 83420 & 70520 & 66740 & 73510 & 55990 & 65660 & 32090 & 26590 & 21370 & 26210 & 17900 & 12280 \\
\hline Copepod nauplii & 112520 & 135580 & 82560 & 101640 & 69270 & 53690 & 13690 & 10970 & 8700 & 11350 & 5250 & 4540 \\
\hline Oikopleura dioica & 3760 & 3370 & 11470 & 12840 & 11270 & 11590 & 19650 & 19320 & 4690 & 6590 & 350 & 300 \\
\hline
\end{tabular}


and length was measured. Mandible plates were measured and using relationships between mandible width, prosome length and prosome width (Karlson \& Båmstedt 1994, Saito \& Kiørboe 2001), digested copepod prey were identified and sized. At times, mandibles were not found even though obvious copepod remains were present. If the remains did not allow species identification, the prey copepod was recorded as unidentified. Appendicularians were detected by their faecal pellets and 3 pellets were assumed to originate from 1 individual (López-Urrutia \& Acuña 1999). Prey chaetognaths were recognised by their grasping spines.

Feeding rates. The feeding rate $\left(\mathrm{FR}_{\mathrm{h}}\right.$, prey $\left.\mathrm{h}^{-1}\right)$ was calculated separately for each depth stratum and for each time (day and night) using the equation of Bajkov (1935):

$$
\mathrm{FR}_{\mathrm{h}}=\mathrm{NPC} / \mathrm{DT}
$$

where NPC is the number of prey per chaetognath and $\mathrm{DT}$ is the digestion time (h). DT was estimated from the equation given in Ohman (1986):

$$
\mathrm{DT}=10.48 \mathrm{e}^{-0.086 T}
$$

where $T$ is the water temperature $\left({ }^{\circ} \mathrm{C}\right)$. In this study, the temperature varied from 9 to $16^{\circ} \mathrm{C}$ in the surface water, and between 5 and $6^{\circ} \mathrm{C}$ in the bottom waters. Temperature corrected DTs are presented in Table 1. We did not multiply the DT by 2 (Feigenbaum 1991), since prey in the anterior gut was not included in the analysis. We then estimated the daily feeding rate (FR, prey $\mathrm{d}^{-1}$ )

$$
\mathrm{FR}=(\text { Mean NPC } \times 24) / \mathrm{DT}
$$

where mean NPC is the mean value of the night and day values. Finally, clearance rates were calculated and used as a measure of selectivity (sensu Saito \& Kiørboe 2001). The clearance $\left(\mathrm{CR}, \mathrm{ml} \mathrm{d}^{-1}\right)$ was calculated as:

$$
\mathrm{CR}=\mathrm{FR} / \mathrm{P}
$$

where $\mathrm{P}$ is the ambient prey concentration (ind. $\mathrm{ml}^{-1}$ ).

\section{RESULTS}

\section{Chaetognath abundance and size distribution}

Sagitta setosa occurred in small numbers (ca. 10 ind. $\mathrm{m}^{-3}$ ) with an average size of $7 \mathrm{~mm}$ at the first sampling date (Figs. 1A \& 2). Nearly all animals were found in the upper $20 \mathrm{~m}$. On 14 September, abundances were 10 times higher and animals 3 to $5 \mathrm{~mm}$ in size dominated. Size increased gradually and abundance peaked on 1 October with 310 ind. $\mathrm{m}^{-3}$ in the
A

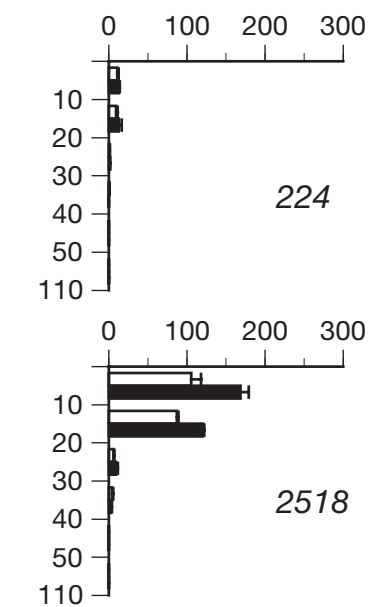

Abundance, ind $\mathrm{m}^{-3}$

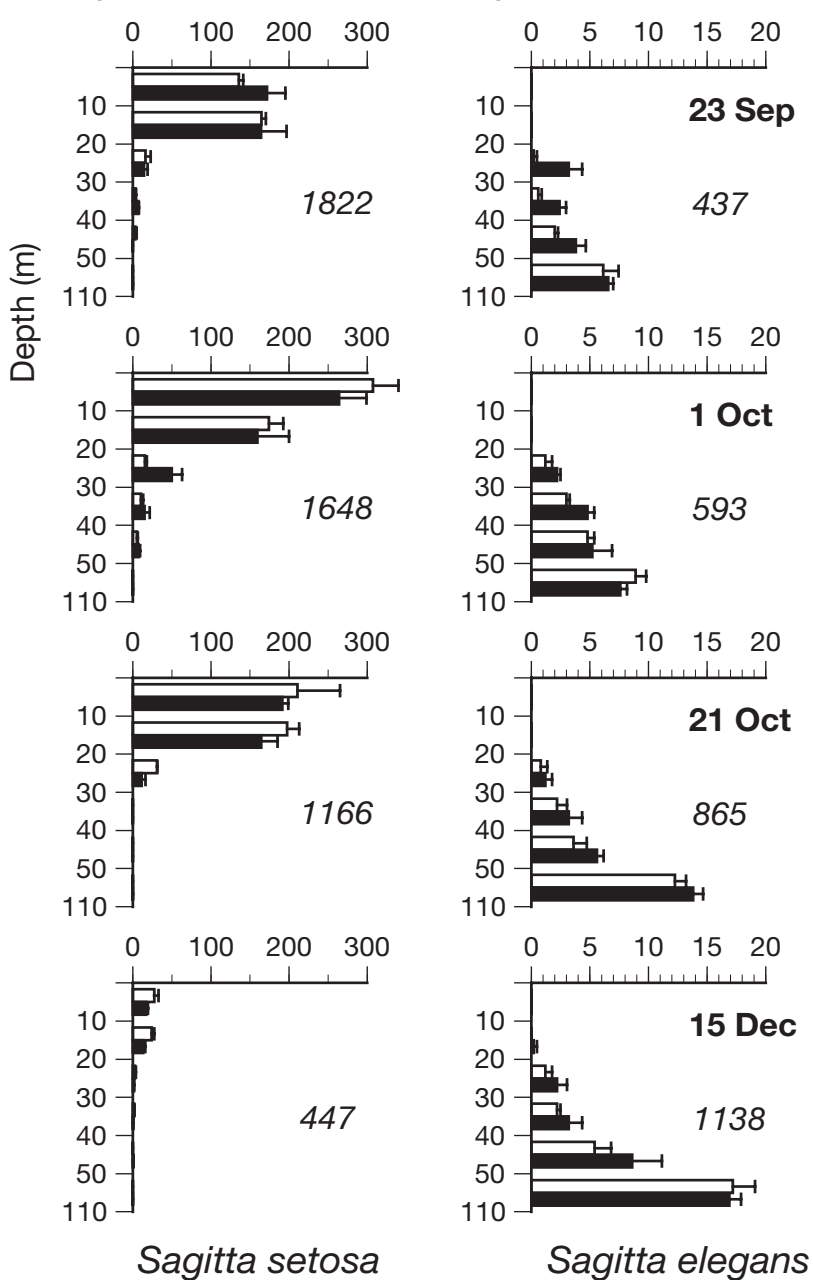

Fig. 1 (above and next 2 pages). Abundance (ind. $\mathrm{m}^{-3}$ ) of zooplankton in the Gullmar fjord 1998. White bars: day; black bars: night. Error bars: $\mathrm{SD}, \mathrm{n}=2$. (A) Sagitta setosa and $S$. elegans. Total number of chaetognaths counted and measured on each date is shown in italics. (B) Paracalanus parvus, Pseudocalanus sp., Acartia clausi and Centropages sp. (C) Calanus finmarchicus, Oithona sp., copepod nauplii and Oikopleura dioica 


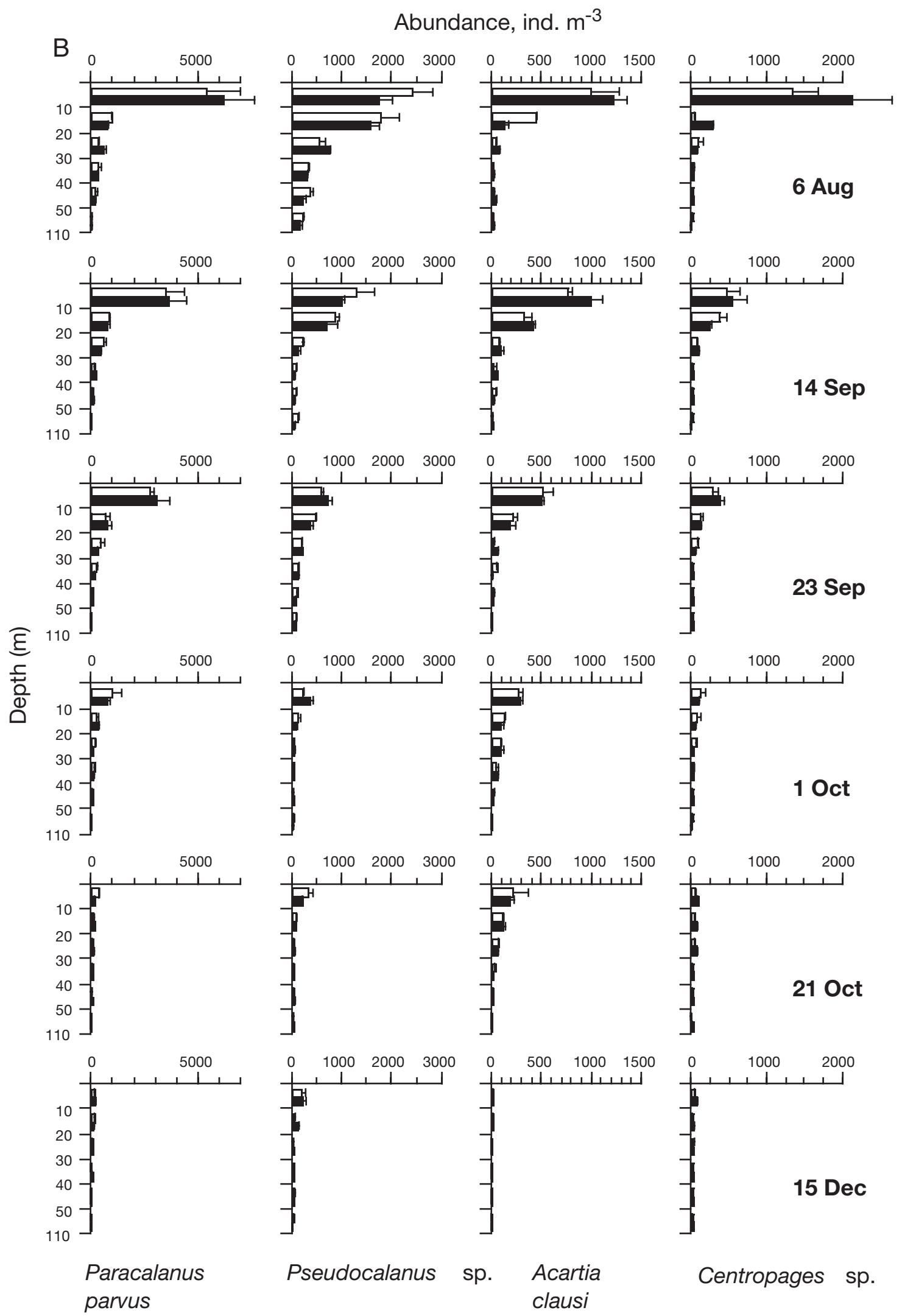

Fig. 1 (continued) 


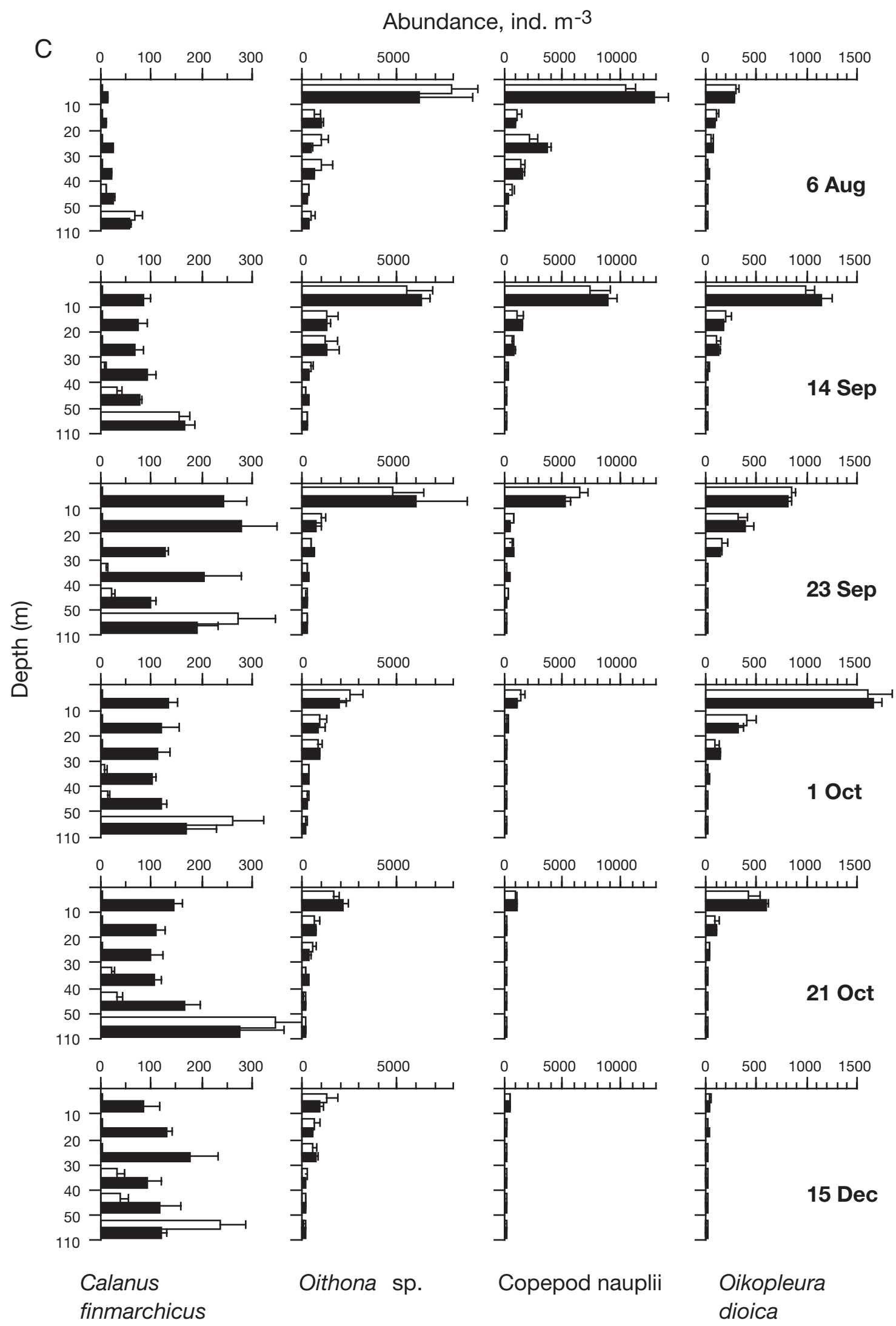

Fig. 1 (continued) 
surface water. The smaller animals then gradually disappeared and the peak at $5 \mathrm{~mm}$ became more pronounced. After 21 October, abundances declined to ca. 20 ind. $\mathrm{m}^{-3}$ on 15 December.

Sagitta elegans was restricted to the deeper parts of the fjord, with abundances gradually increasing from 5 to 17 ind $\mathrm{m}^{-3}$ in the depth interval of $50-110 \mathrm{~m}$ (Fig. 1A). The size distribution was entirely separated from $S$. setosa, with the total length of animals ranging from 14 to $32 \mathrm{~mm}$ (Fig. 2). A gradual shift in size was observed and median length increased from 20 to $26 \mathrm{~mm}$ during the study.

\section{Prey abundance}

Prey abundance showed no consistent differences between day and night, and the averages were used for comparisons between depths and dates (Fig. 1B,C). The exception was Calanus finmarchicus, which was a dominant prey for Sagitta elegans and showed strong vertical migration. Highest abundances were recorded for Paracalanus parvus (maximum 6100 ind. $\mathrm{m}^{-3}$, Fig. 1B), Oithona (7800 ind. $\mathrm{m}^{-3}$, Fig. 1C) and copepod nauplii (12700 ind. $\mathrm{m}^{-3}$, Fig. 1C) on the first sampling date. These prey organisms were concentrated in the surface layer and were 5 to 10 times less abundant below $10 \mathrm{~m}$. Pseudocalanus sp. (maximum 2413 ind. $\mathrm{m}^{-3}$, Fig. 1B), which was the most common prey in the guts of $S$. setosa, equalled $P$. parvus in abundance at 10-20 m, but was not as abundant at the surface. Prey abundance declined over time except that $S$. setosa and Oikopleura dioica peaked on 1 October, and C. finmarchicus copepodites reached highest abundances on 23 September (Fig. 1C).

Total prey abundance ranged from 28000 to 1900 ind. $\mathrm{m}^{-3}$ in the $0-10 \mathrm{~m}$ layer and from 4700 to 900 ind. $\mathrm{m}^{-3}$ in the 10-20 m layer (Fig. 3). Abundance was higher in the 0-10 $\mathrm{m}$ layer for all prey that were permanently present in the 0 to $20 \mathrm{~m}$ layer (repeated 1-factor ANOVAs for each date, df $=1,2, p<$ 0.03). There was no difference between night and day prey distributions.

\section{Gut content}

The guts of 7825 Sagitta setosa were examined and 4108 contained prey. $S$. setosa ingested copepods, appendicularians and smaller conspecifics when abundant (Fig. 4A). In the 0-10 m depth stratum, copepodites contributed 50 to $75 \%$ of the diet in August-September, with smaller contributions from nauplii Oikopleura dioica and unidentified copepods. O. dioica and S. setosa increased over time, and in October together contributed approximately $50 \%$ of prey in the guts. The pattern was the same at 10-20 m, but with a slightly smaller contribution from nauplii. Of the $3764 S$. elegans examined for gut content, 1384 contained 1 or more prey.
Fig. 2. Sagitta setosa and $S$. elegans. Length frequency distributions. For $S$. setosa, only animals from 0 to $20 \mathrm{~m}$ are included; for $S$. elegans, all individuals found are included. Number of analysed animals is shown in italics 


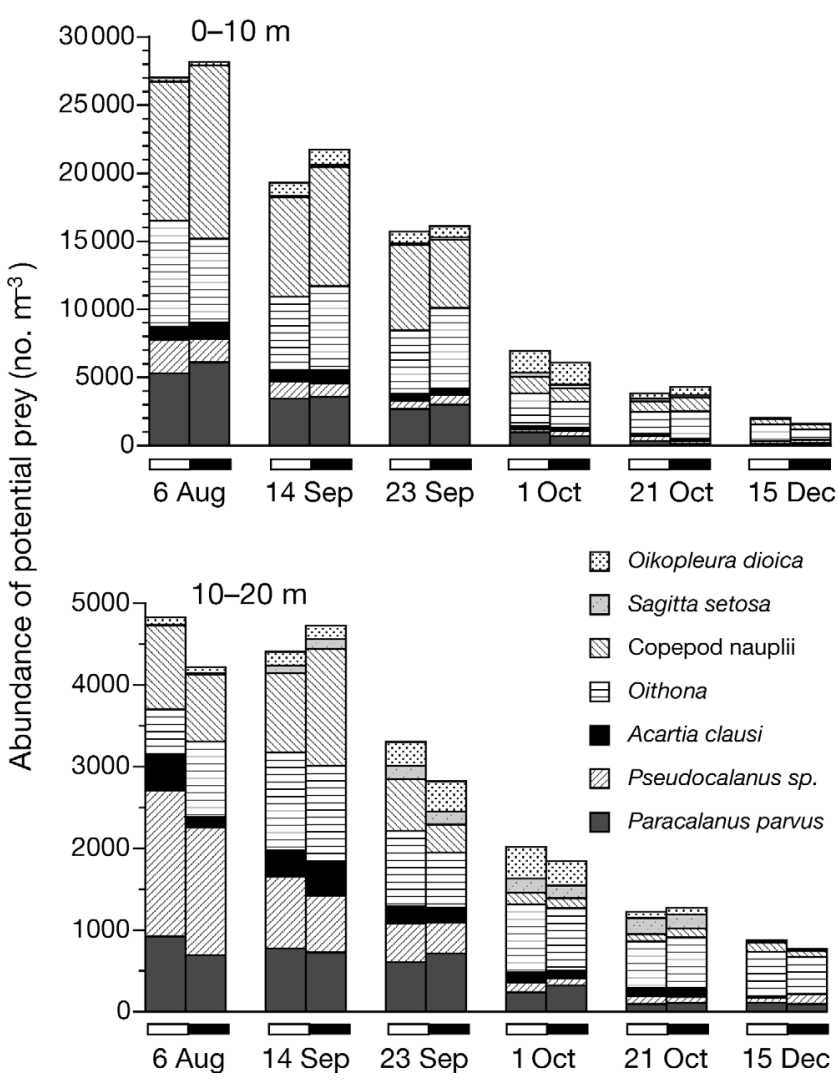

Fig. 3. Sagitta setosa. Total abundance of potential prey (ind. $\mathrm{m}^{-3}$ ) summed for $0-10$ and $10-20 \mathrm{~m}$. Note different $y$-axis scales. Bars below columns indicate day and night samples

Calanus finmarchicus copepodites were the dominant prey for $S$. elegans, constituting 70 to $80 \%$ of the diet (Fig. 5).

\section{NPC}

NPC of Sagitta setosa ranged from 0.2 to 1.0 prey ind..$^{-1}$ in the upper $20 \mathrm{~m}$, where most of the animals were found (Fig. 6). There was a strong diurnal feeding rhythm at both $0-10$ and $10-20 \mathrm{~m}$ (separate 2 -factor ANOVAs, $d f=1,12, p<0.001) ; 57$ to $97 \%$ higher values were recorded at night. The animals from the 0-10 m interval had a significantly higher NPC than chaetognaths from 10-20 m (2-factor ANOVA, df = $1,44, \mathrm{p}<0.001)$. There was a significant decline in NPC with time in the $0-10 \mathrm{~m}$ layer (2-factor ANOVA, $\mathrm{df}=5,12, \mathrm{p}=0.0022$ ) but this was not evident at 10-20 m. Animals from deeper layers were scarce and showed no significant temporal or spatial variation.

NPC in Sagitta elegans ranged from 0.4 to 0.9 prey ind.$^{-1}$ in the $50-110 \mathrm{~m}$ depth interval and there was a significant diurnal feeding rhythm (2-factor ANOVA,

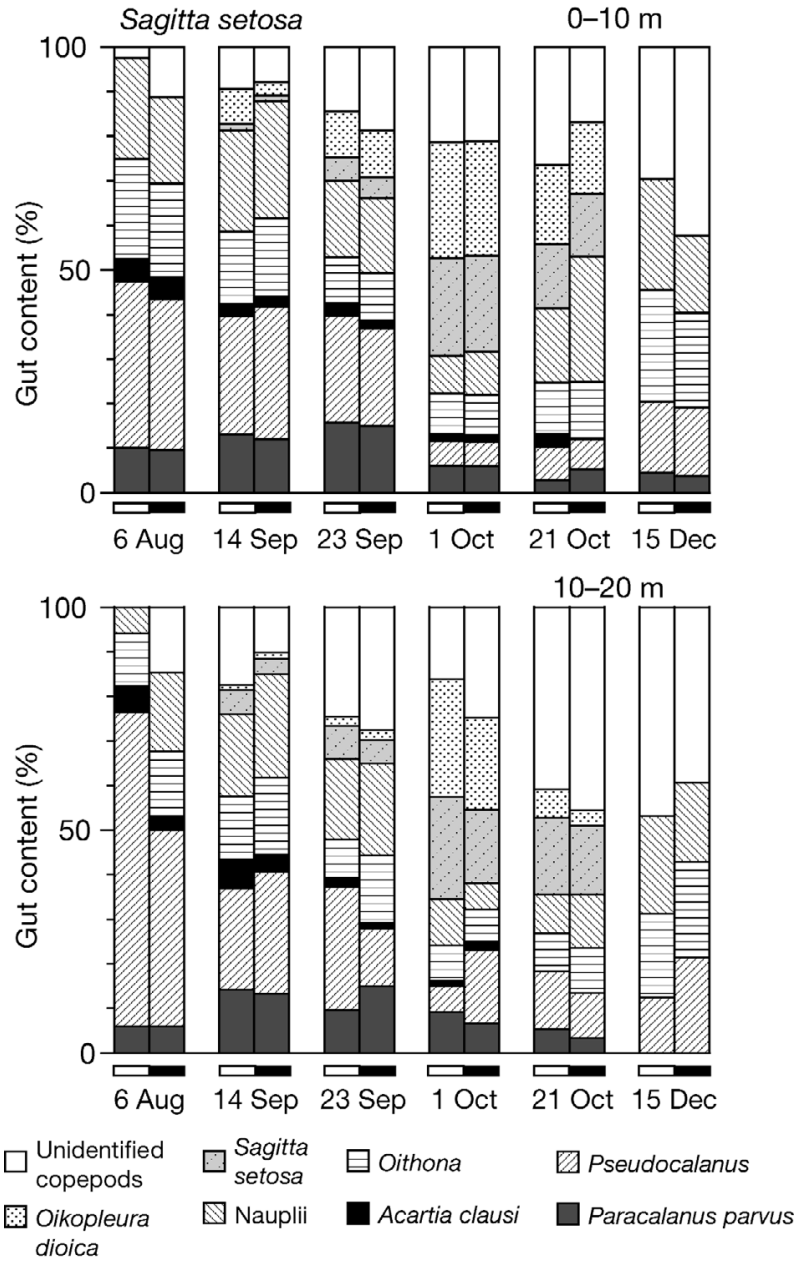

Fig. 4. Sagitta setosa. Gut content (\%) of chaetognaths from 2 depth intervals. Percentage is calculated from number of prey found in the gut. Bars below columns indicate day and night samples

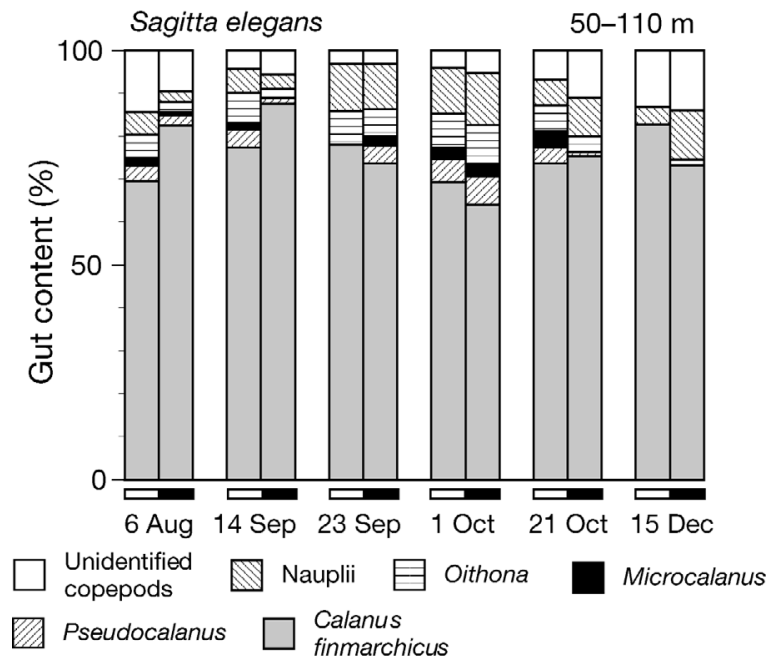

Fig. 5. Sagitta elegans. Gut content (\%) of chaetognaths from $50-110 \mathrm{~m}$. Percentage is calculated from number of prey found in the gut. Bars below columns indicate day and night samples 


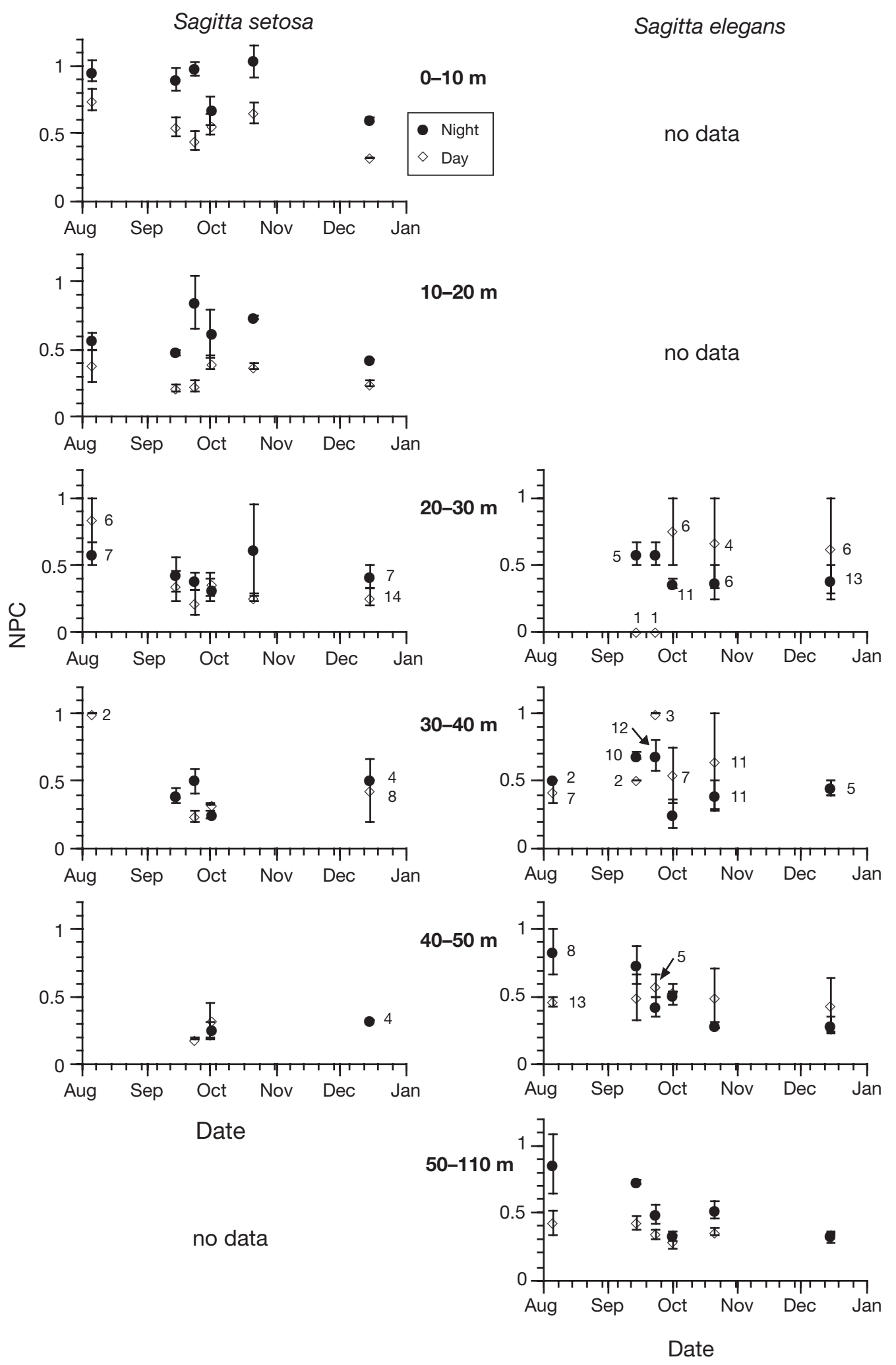

Fig. 6. Sagitta setosa and S. elegans. Number of prey chaetognath ${ }^{-1}$ (NPC) in the Gullmar fjord August to December 1998. 'No data' indicates that no animals were found in these depth strata. Values next to symbols indicate number of animals analysed and are presented when $<15$ animals were found. Error bars are \pm SE 
$\mathrm{df}=1,12, \mathrm{p}=0.0018$ ), with about $50 \%$ higher values at night. NPC declined significantly over time (2-factor ANOVA, $\mathrm{df}=1,5, \mathrm{p}=0.006$ ) because night-time values declined. The daytime values were almost constant in the 2 deepest layers $(0.43 \pm 0.03, \mathrm{SE}, \mathrm{n}=24)$. The data from water layers above $40 \mathrm{~m}$ did not show any significant spatial or temporal differences. There was no difference in NPC when comparing night-time recordings at 40-50 and 50-110 m (2-factor ANOVA, $\mathrm{df}=1,12, \mathrm{p}=0.63$ ), but daytime values were significantly higher at 40-50 m (2-factor ANOVA, $\mathrm{df}=1,12, \mathrm{p}=0.04$ ).

The position of prey in the gut of Sagitta setosa did not vary even though NPC was higher at night (Table 2). A total of 40 to $80 \%$ of the prey were in Position 2. In $S$. elegans, there were no diurnal difference in prey position either, and 55 to $75 \%$ of the prey were in Position 2.

Feeding rates were calculated from NPC, and since the digestion times are temperature-dependent, the cooling of surface waters during the study augmented the effect of declining NPC for Sagitta setosa. Feeding rates based on average NPC ranged from 5.9 to 3.9 prey ind.$^{-1} \mathrm{~d}^{-1}$ in August-October but declined to 2.0 in December for $S$. setosa. Feeding rates of $S$. elegans closely followed changes in the NPC because of the constant digestion time in the deep water and ranged from 2.6 to 1.6 prey ind..$^{-1} \mathrm{~d}^{-1}$.

\section{Clearance of different prey}

A comparison of prey abundance (Fig. 3) and gut content (Fig. 4) for Sagitta setosa within the same depth stratum shows that prey were not eaten in proportion to occurrence, which indicates selective feeding. As prey abundance in the deeper strata was integrated over $50-110 \mathrm{~m}$, co-occurrence cannot be assumed and this prevents a deeper analysis of prey selectivity of $S$. elegans.

To investigate selectivity of Sagitta setosa, daily clearance for each prey type was calculated. Clearance is a convenient measure of selectivity if prey abundance is variable and ingestion rates are not saturated (Saito \& Kiørboe 2001). To evaluate a potential saturation effect, we used all estimates of temperature-corrected ingestion rates transformed to carbon ingestion and plotted these against prey carbon available. Ingestion increased linearly with prey concentration and no sign of saturation was found (Fig. 7); thus, relative clearance was considered a valid measure of prey selection by chaetognaths.
Clearance for most prey increased to a peak in October and then declined again in December, but the selectivity pattern did not differ between the dates. In Fig. 8, all the clearance estimates from the study period have been pooled to an average volume for day and night for each prey type. All clearances were higher at night ( 3 -factor ANOVA, df $=1,115, \mathrm{p}<0.0015$ ). Average clearance ranged from 11 to $124 \mathrm{ml} \mathrm{ind.}^{-1} \mathrm{~d}^{-1}$, with highest values at night for Pseudocalanus sp. $(120 \mathrm{ml}$ ind. $\left.{ }^{-1} \mathrm{~d}^{-1}\right)$, Sagitta setosa $\left(124 \mathrm{ml}\right.$ ind..$\left.^{-1} \mathrm{~d}^{-1}\right)$ and copepod nauplii $\left(88 \mathrm{ml}\right.$ ind. $\left.{ }^{-1} \mathrm{~d}^{-1}\right)$. Clearance was significantly higher for Pseudocalanus sp. and S. setosa (SNK-test,) whereas the clearance of other prey types did not differ significantly.

Clearance in Sagitta elegans was only calculated for the depth strata above $50 \mathrm{~m}$ because co-occurrence cannot be assumed in the deepest layer. The major

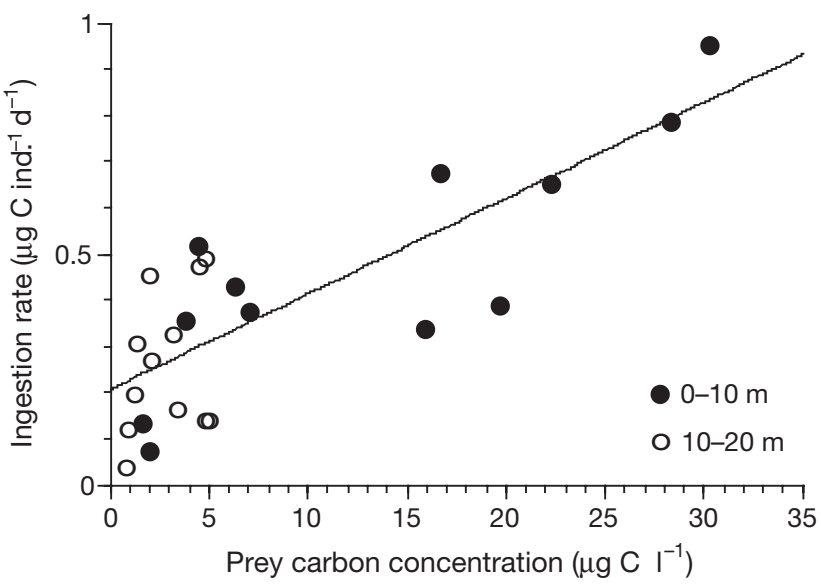

Fig. 7. Sagitta setosa. Functional response of ingestion rate ( $\mu \mathrm{gC}$ ind. ${ }^{-1} \mathrm{~d}^{-1}$ ) to increasing prey carbon concentration $\left(\mu \mathrm{g} \mathrm{C}^{-1}\right)$. Prey carbon was estimated from length-weight regressions in Mauchline (1998, copepods), Conway \& Robins (1991, chaetognaths) and Paffenhöfer (1976, appendicularians). Each circle represents the estimated ingestion rate of all prey types from 1 tow. Regression line for all data: $0.021 x+0.21, \mathrm{n}=24, \mathrm{R}^{2}=0.69$

Table 2. Sagitta setosa and S. elegans. Position of prey in the gut of investigated chaetognaths, considering only animals with prey in the middle or posterior part of the gut (Positions 2 and 3, sensu Øresland 1987, his Fig. 1). Numbers show the percentage of prey in Position 2 out of the total number of prey found in Positions 2 and 3. Bold indicates night values

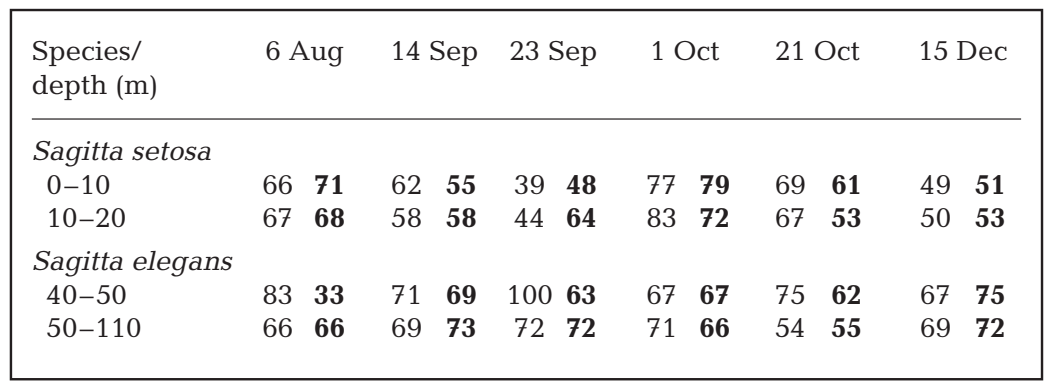



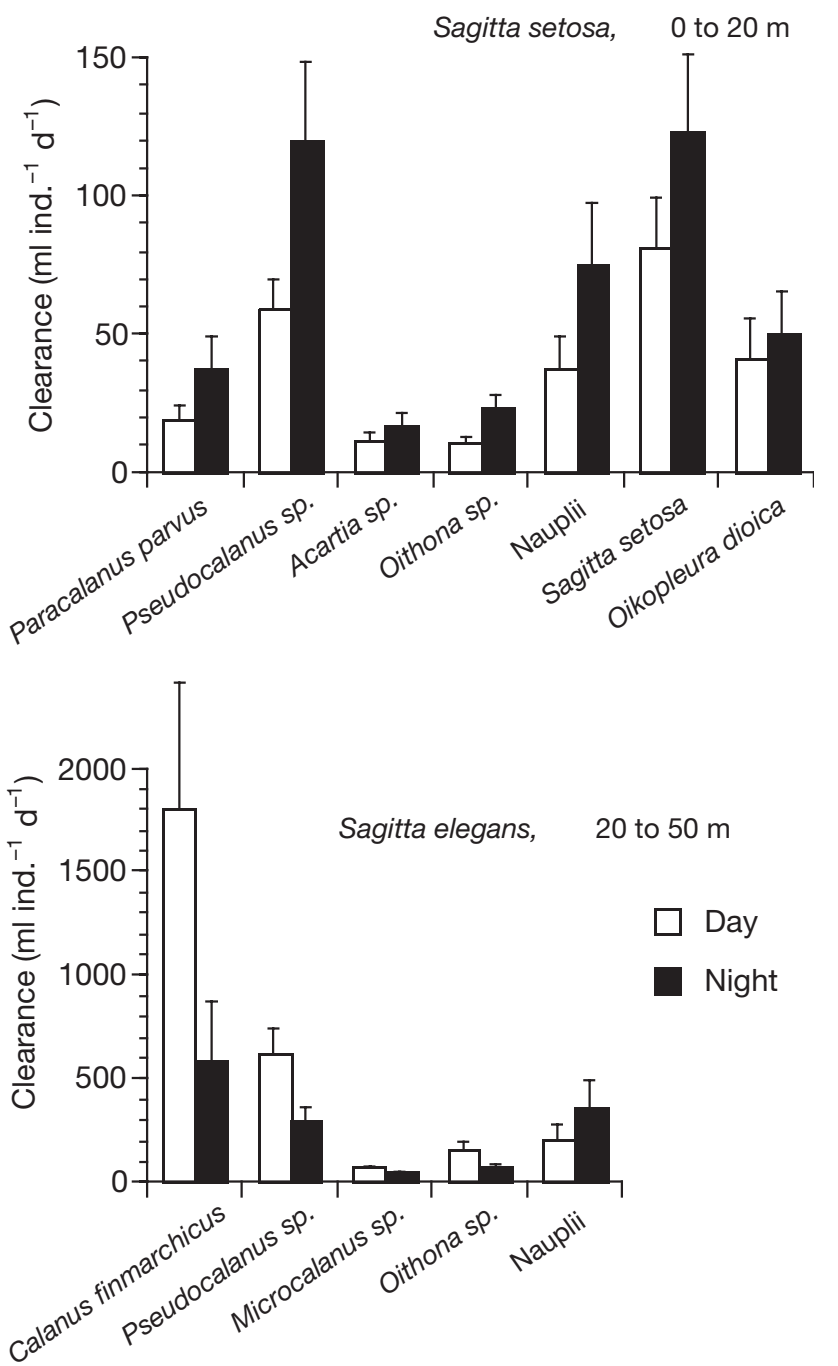

Fig. 8. Sagitta setosa and S. elegans. Estimated clearance (ml ind..$^{-1} \mathrm{~d}^{-1}$ ) on various prey. Clearance estimated from feeding rates (prey ind.$^{-1} \mathrm{~d}^{-1}$ ) divided by ambient concentration (prey $\mathrm{ml}^{-1}$ ) at each depth interval and day/night. Data for all 6 sampling dates are pooled. Error bars are $\pm \mathrm{SE}, \mathrm{n}=8$ to 12

part of the population resided below this depth and therefore, the clearance estimates should be viewed with some caution. Since NPC was significantly higher at night and the main prey organism Calanus finmarchicus is a strong migrator (Fig. 1C), the night-time clearances are most accurate. Clearance ranged from 100 to $600 \mathrm{ml}$ ind..$^{-1} \mathrm{~d}^{-1}$ but reached 3 times higher values when estimated from day time prey abundances.

\section{DISCUSSION}

Nearly all Sagitta setosa were found in the upper $20 \mathrm{~m}$, which is in accordance with results from the inner Oslofjord (Jakobsen 1971). Maximum integrated abundances (5110 ind $\mathrm{m}^{-2}$ ) were similar to a maximum of 9440 ind. $\mathrm{m}^{-2}$ reported from the Gullmar fjord (Øresland 1985) and 4000 to 22000 ind. $\mathrm{m}^{-2}$ from Southern Kattegat (Øresland 1983). The seasonal trend in abundance also agrees with previous reports (Jakobsen 1971, Eriksson 1973, Øresland 1985). S. elegans were generally found below $50 \mathrm{~m}$ which agrees with Jakobsen (1971) and did not perform vertical migration in the Gullmar fjord. S. elegans abundances gradually increased during the study period but, in contrast to $S$. setosa, the population is present throughout the year in the Gullmar fjord (Øresland 1985).

The abundance of prey for Sagitta setosa decreased during the study except for the increase of Oikopleura dioica and conspecifics. Chaetognaths readily feed on appendicularians and their contribution to the diet can be important at times (5 to $41 \%$, Kimmerer 1984). In the Gullmar fjord $26 \%$ of the diet consisted of $O$. dioica at their peak abundance. The food availability for $S$. elegans was relatively invariant since Calanus copepodites dominated the diet and their abundance did not change throughout the study. The seasonal decrease in smaller zooplankton biomass is in accordance with previous studies (Eriksson 1973, Lindahl \& Hernroth 1988, Hay et al. 1991, Kiørboe \& Nielsen 1994).

NPC values for Sagitta setosa and $S$. elegans were among the highest reported for chaetognaths (Øresland 1987, Kehayias et al. 1996, Baier \& Purcell 1997b, Saito \& Kiørboe 2001). Although we do not know whether S. setosa experienced food-limited growth, the high NPC are probably related to the high prey abundance above the permanent halocline. The estimated daily ration for $S$. setosa ranged from $23 \%$ in August to $3 \%$ in December. These values are similar to those for $S$. hispida, which was assumed to require daily ration of about $10 \%$ to sustain maximum growth and reproduction (Feigenbaum \& Reeve 1977). In warm waters, the daily ration for $S$. enflata ranged from 18 to $40 \%$ of body weight (Kimmerer 1984). Interestingly, S. setosa managed to keep a ration of 11 to $17 \%$ during September-October despite a dramatic decrease in prey abundance. It did so by including appendicularians and conspecifics in the diet to such an extent that cannibalism reached $84 \% \mathrm{~d}^{-1}$. The estimated daily rations indicate that $S$. setosa was foodlimited at least on some dates, and that a high NPC can be expected when prey is abundant.

High NPCs might also be due to the short duration of the tows. Several earlier reports have stressed the potential overestimation of NPC due to cod-end feeding, but this concern is apparently unfounded (Baier \& Purcell 1997a). On the contrary, prey loss during sampling may be a more serious problem during long tows. We strived to keep tows short and the high NPCs in this study are probably more realistic than previous reports. 
NPC and digestion times (DT) were used to estimate predation impact. Digestion times are not well known for Sagitta setosa and we have applied DTs from studies of $S$. elegans. The main factors affecting DT are temperature, number of prey in the gut and size of prey. Type of prey is probably also important, but we used the same DT irrespective of number and type of prey due to lack of published data. Reeve (1980) found that DT was proportional to the number of prey in the gut of $S$. hispida. Multiple prey were found in 3 to $10 \%$ of the $S$. setosa that contained prey in this study, so the error of using a single DT at each date is small. Size of prey, however, may have a stronger effect on DT for S. setosa. Øresland (1987) investigated DT in $S$. elegans (15 to $21 \mathrm{~mm}$ ) with 3 sizes of prey, and found a longer DT for large prey (Calanus CIV-CVI, $9.33 \mathrm{~h}$ ) than for small copepods $(4.90 \mathrm{~h})$. For a similar-sized prey, DT may thus be correspondingly longer for $S$. setosa than predicted for $S$. elegans by the regression in Ohman (1986). The only reported DTs for $S$. setosa are from Mironov (1960), who found a temperature-dependent (11.5 to $20^{\circ} \mathrm{C}$ ) DT of 1 to $2 \mathrm{~h}$ for $S$. setosa feeding on Paracalanus parvus, Acartia clausi and Oithona minuta in the Black Sea. These are approximately half the times used in our study, but we have chosen the conservative estimate of Ohman (1986) since it integrates published data from several sources. If prey size is important, DTs for $S$. setosa may be underestimated and the feeding rates, consequently, overestimated.

\section{Predation impact}

Predation impact was high on copepods and highest on Pseudocalanus sp. where 26 to $48 \%$ of the population was removed daily when Sagitta setosa was abundant (Table 3). Predation impact on copepod

Table 3. Sagitta setosa and S. elegans. Predation impact on prey population $\left(\% \mathrm{~d}^{-1}\right)$ calculated by summing day and night impacts estimated from total abundance of predators and prey

\begin{tabular}{|lcccccc|}
\hline Predator/prey & 6 Aug & 14 Sep & 23 Sep & 1 Oct & 21 Oct & 15 Dec \\
\hline Sagitta setosa & & & & & & \\
$\quad$ Paracalanus parvus & 0.2 & 3.1 & 5.8 & 10.5 & 29.3 & 0.8 \\
Pseudocalanus sp. & 1.4 & 16.5 & 26.2 & 34.5 & 48.1 & 4.2 \\
Acartia Clausi & 0.4 & 2.3 & 3.8 & 6.8 & 4.4 & 0 \\
Oithona sp. & 0.3 & 2.5 & 2.6 & 5.5 & 8.8 & 1.2 \\
Copepod nauplii & 0.2 & 2.6 & 4.6 & 12.8 & 33.9 & 3.3 \\
$\quad$ Sagitta setosa & 0 & 8.6 & 22.8 & 83.9 & 74.3 & 0 \\
$\quad$ Oikopleura diocia & 0 & 2.9 & 8.7 & 23.2 & 41.5 & 0 \\
Sagitta elegans & & & & & & \\
$\quad$ Calanus finmarchicus & 18.0 & 9.0 & 4.6 & 5.3 & 5.4 & 11.9 \\
\hline
\end{tabular}

nauplii showed a steady increase over time, from 3 to $34 \% \mathrm{~d}^{-1}$ and the pattern was similar for Paracalanus parvus, 3 to $29 \% \mathrm{~d}^{-1}$. Predation impact by $S$. elegans was only calculated for the dominant prey organism Calanus finmarchicus. In August, the impact in the 40-50 and 50-110 $\mathrm{m}$ depth strata was $18 \% \mathrm{~d}^{-1}$. Impact then declined as the $C$. finmarchicus population grew faster than the $S$. elegans and ranged from 5 to $9 \% \mathrm{~d}^{-1}$ through October. In December, peak abundance of $S$. elegans was found and impact increased to $12 \% \mathrm{~d}^{-1}$

Predation impact was very high compared to previous reports. Sagitta enflata removed 4 and $6 \%$ of the populations of Oithona simplex and Acrocalanus inermis, respectively (Kimmerer 1984). Stuart \& Verheye (1991) found that 1 to $5.3 \%$ of the copepod standing stock was consumed each day by a $S$. friderici population. Sameoto (1973) reported that $S$. elegans removed more than a third of the annual copepod production in a Canadian inlet. Drits \& Utkina (1988) estimated that $S$. setosa in the Black Sea consumed 0.3 to $6 \%$ of the standing stock of Calanus and Pseudocalanus sp. The high NPC and high chaetognath abundance are the most likely reasons for the high impact, but underestimated DTs may also contribute as discussed above.

Strong predation impact is expected to have effects on the copepod populations. Between 6 August and 14 September, copepod biomass declined ca. $1 \% \mathrm{~d}^{-1}$, as estimated from data in Fig. 3. From 14 September to 21 October, Sagitta setosa abundance increased from 100 to $300 \mathrm{~m}^{-3}$ and the daily copepod biomass loss rate increased to $4.7 \%$, as estimated from an exponential regression of copepod biomass on time (n $=4, \mathrm{R}^{2}=0.87$ ). This indicates that there must have been production or immigration of copepods since daily loss rate did not correspond to predation impact and there are also other predators of copepods. Kiørboe \& Nielsen (1994) reported a potential growth rate of the copepods of $8 \% \mathrm{~d}^{-1}$ during autumn in southern Kattegat and an observed rate of change of copepod biomass of $-1.3 \% \mathrm{~d}^{-1}$. With an observed rate of $-4.7 \% \mathrm{~d}^{-1}$, either copepod production is lower or predation is much stronger in the Gullmar fjord. We did not measure production of copepods, but it should be similar to that in the southern Kattegat. Øresland (1985) showed that S. setosa was less abundant in the fjord compared to outside, so even if predation impact was high at our sampling station, it could potentially be even higher outside the fjord. Thus, the local predation impact on copepods is high but the exact magnitude requires a measure of local prey production. 
The predation impact on Oikopleura dioica was substantial, 23 to $42 \% \mathrm{~d}^{-1}$ in October. Strong predation on appendicularians has previously been reported by Kimmerer (1984), who found that the daily chaetognath consumption of $O$. longicauda could periodically reach $200 \% \mathrm{~d}^{-1}$. O. dioica has a very high growth rate, which can allow strong predation without drastic population declines. At the time of peak $S$. setosa abundance, copepod prey were severely reduced and $O$. dioica became an important part of the diet.

\section{Cannibalism}

The highest predation impact of Sagitta setosa was on conspecifics, and cannibalism is known to be important in chaetognaths (Szyper 1978, Feigenbaum 1979, Pearre 1982, Øresland 1987, Stuart \& Verheye 1991). Kimmerer (1984) found that $S$. enflata predation on average removed $5 \% \mathrm{~d}^{-1}$ and up to $32 \% \mathrm{~d}^{-1}$ of the Sagitta population. Øresland (1987) estimated that $50 \%$ of the population of $S$. setosa could be eaten in $4 \mathrm{~d}$ and attributed the sharp decline during autumn to cannibalism. Cannibalism peaked on 1 October when $84 \%$ of the population was eaten each day. On that date, $14 \%$ of the chaetognaths were found with another chaetognath in their gut. Pearre (1982) presented a model where the cannibalism (expressed as proportion of chaetognaths in the diet) can be estimated from mouth width and chaetognath abundance. With observed maximum abundances (Fig. 1) and median size (Fig. 2, converted to mouth width, Pearre 1982) for the date of maximum cannibalism (1 October), Pearre's (1982) regression would predict that $19 \%$ of $S$. setosa would have congenerics in their guts. This value is close to our observed proportion of $23 \%$ (Fig. 4). The regression is sensitive to mouth width, but the estimate indicates that the abundant $S$. setosa and their high feeding activity can explain the uniquely high cannibalism.

Between 21 October and 15 December, the Sagitta setosa population decreased from around 200 to 20 ind. $\mathrm{m}^{-3}$. This decline cannot entirely be due to cannibalism, as other invertebrates and fish must also have exerted considerable pressure, but the cannibalism is quantified in the present study. The chaetognath population clearly did not decline as drastically as the predation impact would predict. One explanation is that most of the cannibalism would target small individuals. Recruitment of young S. setosa can occur both from advection into the fjord and local production. Øresland (1987) emphasises the transport of chaetognaths into the fjord during autumn, and it could partly explain the pattern, given that predation outside the fjord was less intense. Production of young
S. setosa is also likely, since breeding takes place from August and throughout the autumn, judging from the state of the ovaries (Øresland 1983). Kimmerer (1984) suggests that estimated impacts on prey populations would be different if prey sizes were considered and this also seemed to be the case for the cannibalism displayed in our study. The small juveniles were highly susceptible to cannibalism, resulting in the decline and absence of small individuals in late October (Fig. 2). The production of small juveniles probably fuelled the cannibalism such that almost all of these newly hatched were eaten by conspecifics. The juvenile production also explains why total abundance did not decline as drastically as may have been expected with such high cannibalism.

\section{Selective feeding}

Predation by Sagitta setosa did not mirror available prey distribution and selective feeding was pronounced. Prey size and motility are important for prey detection in rheotactic chaetognaths. Paracalanus parvus was the most abundant calanoid copepod, yet the clearance was only one third of that of Pseudocalanus sp. Selection may be explained by the size and motility of the prey through a hydrodynamic analysis (Kimmerer 1984, Saito \& Kiørboe 2001). Assuming that $S$. setosa behaves like $S$. elegans, we estimate reaction distances of $P$. parvus and Pseudocalanus sp. to 2.2 and $4.5 \mathrm{~mm}$, respectively. Both are longer than the $0.88 \mathrm{~mm}$ measured for S. hispida (Feigenbaum \& Reeve 1977), but reasonable given the assumptions in the calculations. The behaviour of the 2 copepods differs considerably even though they are of similar size (Tiselius \& Jonsson 1990). A longer reaction distance means that Pseudocalanus sp. will be detected further away, which explains part of the higher clearance on this species. The other small copepods Acartia clausi and Oithona sp. are cleared at lower rates due to their limited motility, mostly sinking and occasionally jumping (Tiselius \& Jonsson 1990).

Clearance was surprisingly high on the large and slow moving Oikopleura dioica. However, O. dioica has a typical tail beat frequency while feeding (Selander \& Tiselius 2003) and Sagitta setosa may detect the vibrations translated to the surrounding water. It may also detect disturbed animals that swim vigorously until they have settled in a new house (Selander \& Tiselius 2003). The latter seems most likely given that an $O$. dioica mucus house is very sticky and would be hard to handle for a chaetognath.

The high clearance on conspecifics displayed by Sagitta setosa is interesting. It implies that either the swimming behaviour of $S$. setosa is different from that of 
S. elegans (ambush) or that turbulence may provide the relative velocity between predator and prey necessary for encounter. Turbulence is generally stronger in shallow waters where $S$. setosa reside. With a long body and large target size, $S$. setosa will encounter many conspecifics in periods of high turbulence. Saito \& Kiørboe (2001) concluded that turbulence did not affect feeding in $S$. elegans and that it only actively fed on moving prey. Øresland (1987) suggested that the absence of cannibalism in his study of $S$. elegans was probably due to different vertical distribution of small and large specimens in the Gullmar fjord. The strong association of $S$. setosa with turbulent and prey-rich surface waters points to an ambush feeding mode since the relative motion of the prey, in this case, is created by factors other than predator swimming. S. setosa is also temporally associated to high prey abundance; breeding takes place from July to December (Øresland 1983), after which it rapidly disappears as a consequence of spawning, starvation and intense cannibalism.

Sagitta elegans preferred the large, active swimmer Calanus, and as an ambush predator it must rely on prey motion for encounter. Calanus prey did not decline during the study and $S$. elegans increased in both abundance and size. It maintains a population in the deeper parts of the fjord and has a long breeding season (March to August, Øresland 1985)

\section{CONCLUSIONS}

We have shown that the 2 chaetognath species in the Gullmar fjord are important predators of copepods, appendicularians and, in the case of Sagitta setosa, of conspecifics. The predation impact in surface waters is among the highest recorded, and the cannibalism is extreme. Selectivity even among seemingly similar prey is pronounced, but the mechanism for this remains unclear. There was a clear discrepancy between estimated impact and observed decline in biomass. Mironov (1960) pointed out that comparing a dynamic value (consumption) with a static one (biomass) when estimating predation impact is not correct. Instead, the predation impact should be estimated using dynamic values, but they are difficult to obtain. Future studies on predation impact should focus on simultaneous measurements of predation and net prey population growth. The dynamics of digestion also deserves further study since the correct determination of digestion time is critical for any predation impact estimate.

Acknowledgements. This study was supported by EC-MAST3 project KEYCOP (MAS3-CT97-0148) and the Carl Trygger Foundation. We are grateful for comments from 4 anonymous referees, which considerably improved the manuscript.

\section{LITERATURE CITED}

Alvarez-Cadena JN (1993) Feeding of the chaetognath Sagitta elegans Verrill. Estuar Coast Sci 36:195-206

Baier C, Purcell JE (1997a) Effects of sampling and preservation on apparent feeding by chaetognaths. Mar Ecol Prog Ser 146:37-42

Baier C, Purcell JE (1997b) Trophic interactions of chaetognaths, larval fish, and zooplankton in the South Atlantic Bight. Mar Ecol Prog Ser 146:43-53

Bajkov AD (1935) How to estimate the daily food consumption of fish under natural conditions. Trans Am Fish Soc 65: 288-289

Conway DVP, Robins DB (1991) Collection and chemical analysis of chaetognaths and changes due to preservation. In: Bone Q, Kapp H, Pierrot-Bults AC (eds) The biology of chaetognaths. Oxford University Press, New York, p $137-146$

Drits AV, Utkina SV (1988) Feeding of Sagitta setosa in the layers of daytime phytoplankton accumulation in the Black Sea. Oceanology 28:781-785

Duró A, Saiz E (2000) Distribution and trophic ecology of chaetognaths in the western Mediterranean in relation to an inshore-offshore gradient. J Plankton Res 22:339-361

Eriksson S (1973) Abundance and composition of Zooplankton on the West Coast of Sweden. ZOON 1:113-123

Feigenbaum DL (1979) Daily ration and specific daily ration of the chaetognath Sagitta enflata. Mar Biol 54:75-82

Feigenbaum DL (1991) Food and feeding behaviour. In: Bone Q, Kapp H, Pierrot-Bults AC (eds) The biology of chaetognaths. Oxford University Press, New York, p 45-54

Feigenbaum DL, Maris RC (1984) Feeding in the Chaetognatha. Oceanogr Mar Biol Annu Rev 22:343-392

Feigenbaum DL, Reeve MR (1977) Prey detection in the Chaetognatha: response to and experimental determination of attack distance in large aquaria. Limnol Oceanogr 22:1052-1058

Hay SJ, Kiørboe T, Matthews A (1991) Zooplankton biomass and production in the North Sea during the Autumn Circulation Experiment, October 1987-March 1988. Cont Shelf Res 11:1453-1476

Jakobsen T (1971) On the biology of Sagitta elegans Verrill and Sagitta setosa J. Müller in inner Oslofjord. Norw J Zool 19:201-225

Karlson K, Båmstedt U (1994) Planktivorous predation on copepods. Evaluation of mandible remains in predator guts as a quantitative estimate of predation. Mar Ecol Prog Ser 108:79-89

Kehayias G, Lykakis J, Fragopoulu N (1996) The diets of the chaetognaths Sagitta enflata, S. serratodentata atlantica and $S$. bipunctata at different seasons in Eastern Mediterranean coastal waters. ICES J Mar Sci 53: 837-846

Kimmerer WJ (1984) Selective predation and its impact on prey of Sagitta enflata (Chaetognatha). Mar Ecol Prog Ser 15:55-62

Kiørboe T, Nielsen TG (1994) Regulation of zooplankton biomass and production in a temperate, coastal ecosystem. 1. Copepods. Limnol Oceanogr 39:493-507

Kott P (1953) Modified whirling apparatus for the subsampling of plankton. Aust J Mar Freshw Res 4:387-393

Lindahl O, Hernroth L (1988) Large-scale and long-term variations in the zooplankton community of the Gullmar fjord, Sweden, in relation to advective processes. Mar Ecol Prog Ser 43:161-171

López-Urrutia Á, Acuña JL (1999) Gut throughput dynamics in the appendicularian Oikopleura diocia. Mar Ecol Prog 
Ser 191:195-205

Mauchline J (1998) The biology of calanoid copepods. Adv Mar Biol 33:1-710

Mironov GN (1960). The food of plankton predators. 2. Food of Sagitta. Tr Sevastop Biol Stn 13:78-88

Ohman MD (1986) Predator-limited population growth of the copepod Pseudocalanus sp. J Plankton Res 8:673-713

Øresland V (1983) Abundance, breeding and temporal size distribution of the chaetognath Sagitta setosa in the Kattegat. J Plankton Res 5:425-439

Øresland V (1985) Temporal size and maturity-stage distribution of Sagitta elegans and occurrence of other chaetognath species in Gullmarsfjorden, Sweden. Sarsia 70: 95-101

Øresland V (1987) Feeding of the chaetognaths Sagitta elegans and $S$. setosa at different seasons in Gullmarsfjorden, Sweden. Mar Ecol Prog Ser 39:69-79

Øresland V (2000) Diel feeding of the chaetognath Sagitta enflata in the Zanzibar Channel, western Indian Ocean. Mar Ecol Prog Ser 193:117-123

Paffenhöfer GA (1976) On the biology of Appendicularia of the southeastern North Sea. In: Persoone G, Jaspers E (eds) Proc 10th Eur Symp Mar Biol, Ostend, Belgium. Sep 17-23, 1975. Universal Press, Wetteren, p 437-455

Pearre S Jr (1973) Vertical migration and feeding in Sagitta elegans Verrill. Ecology 54:300-314

Pearre S Jr (1974) Ecological studies of three WestMediterranean chaetognaths. Invest Pesq 38:325-369

Pearre S Jr (1980) Feeding by Chaetognatha: the relation of prey size to predator size in several species. Mar Ecol Prog Ser 3:125-134

Pearre S Jr (1981) Feeding by Chaetognatha: energy balance

Editorial responsibility: Otto Kinne (Editor-in-Chief), Oldendorf/Luhe, Germany and importance of various components of the diet of Sagitta elegans. Mar Ecol Prog Ser 5:45-54

Pearre S Jr (1982) Feeding by chaetognatha: aspects of interand intra-specific predation. Mar Ecol Prog Ser 7:33-45

Rakusa-Suszczewski S (1967) The use of chaetognath and copepod population age-structures as an indicator of similarity between water masses. J Cons Perm Int Explor Mer 31:46-55

Reeve MR (1980) Comparative experimental studies on the feeding of chaetognaths and ctenophores. J Plankton Res 2:381-393

Saito H, Kiørboe T (2001) Feeding rates in the chaetognath Sagitta elegans: effects of prey size, prey swimming behaviour and small-scale turbulence. J Plankton Res 23: 1385-1398

Sameoto DD (1973) Annual life cycle and production of the chaetognath Sagitta elegans in bedford Basin, Nova Scotia. J Fish Res Board Can 30:333-344

Selander E, Tiselius P (2003) Effects of food concentration on the behaviour of Oikopleura dioica. Mar Biol 142:263-270

Stuart V, Verheye HM (1991) Diel migration and feeding patterns of the chaetognath, Sagitta friderici, off the west coast of South Africa. J Mar Res 49:493-515

Sullivan BK (1980) In situ feeding behaviour of Sagitta elegans and Eukrohnia hamata (Chaetognatha) in relation to the vertical distribution and abundance of prey at Ocean Station 'P'. Limnol Oceanogr 25:317-326

Szyper JP (1978) Feeding rate of the chaetognath Sagitta enflata in nature. Estuar Coast Mar Sci 7:567-575

Tiselius P, Jonsson PR (1990) Foraging behaviour of six calanoid copepods: observations and hydrodynamic analysis. Mar Ecol Prog Ser 66:23-33

Submitted: June 24, 2003; Accepted: November 11, 2004 Proofs received from author: March 9, 2005 